\title{
Community-Based Cardiac Rehabilitation Conducted in a Public Health Center in South Korea: A Preliminary Study
}

\author{
Sora Baek, MD, $\mathrm{PhD}^{1,2,3}$, Yuncheol Ha, $\mathrm{PT}^{1,2}$, Jaemin Mok, SW ${ }^{1,4}$ \\ Hee-won Park, $\mathrm{MD}^{2,3}$, Hyo-Rim Son, $\mathrm{RN}^{5}$, Mi-Suk Jin, $\mathrm{PT}^{6}$
}

\begin{abstract}
${ }^{1}$ Kangwon Regional Cardiocerebrovascular Center, Kangwon National University Hospital, Chuncheon;
${ }^{2}$ Department of Rehabilitation Medicine, Kangwon National University Hospital, Chuncheon;

${ }^{3}$ Department of Rehabilitation Medicine, Kangwon National University School of Medicine, Chuncheon;

${ }^{4}$ Division of Public Health, Kangwon National University Hospital, Chuncheon;

${ }^{5}$ Hongcheon County Hypertension and Diabetes Registration and Education Center, Hongcheon-gun;

${ }^{6}$ Hongcheon Public Health Center, Hongcheon-gun, Korea
\end{abstract}

Objective To evaluate the safety and effectiveness of the community-based cardiac rehabilitation (CBCR) program that we had developed.

Methods Individuals aged $>40$ years with cardiovascular disease or its risk factors who were residing in a rural area were recruited as study subjects. The CBCR program, which consisted of 10 education sessions and 20 weeks of customized exercises (twice a week), was conducted in a public health center for 22 weeks. Comprehensive outcomes including body weight, blood glucose level, and 6-minute walk distance (6MWD) were measured at baseline, 11th week, and completion. Furthermore, the outcomes of young-old (65-74 years) and old-old ( $\geq 75$ years) female subjects were compared.

Results Of 31 subjects, 21 completed the program (completion rate, 67.7\%). No adverse events were observed, and none of the subjects discontinued the exercise program because of chest pain, dyspnea, and increased blood pressure. Body weight and blood glucose level were significantly decreased, and 6MWD was significantly increased following program implementation $(\mathrm{p}<0.05)$. Both young-old and old-old women exhibited an improvement in blood glucose level and 6MWD test $(\mathrm{p}<0.05)$.

Conclusion We reported the results of the first attempted CBCR in South Korea that was implemented without adverse events during the entire program. Improved aerobic exercise ability and reduced risk factors in all participants were observed. These improvements were also achieved by older adults aged $\geq 75$ years.

Keywords Aging, Cardiac rehabilitation, Cardiovascular diseases, Community health centers, Exercise

Received April 23, 2020; Revised May 27, 2020; Accepted June 10, 2020; Published online December 31, 2020

Corresponding author: Sora Baek

Department of Rehabilitation Medicine, Kangwon National University Hospital, Kangwon National University School of Medicine, 156 Baengnyeongro, Chuncheon 24289, Korea. Tel: +82-33-258-9262, Fax: +82-33-25-9097, E-mail: sora.baek@kangwon.ac.kr

ORCID: Sora Baek (https://orcid.org/0000-0003-3404-6202); Yuncheol Ha (https://orcid.org/0000-0001-9140-5713); Jaemin Mok (https://orcid. org/0000-0001-6196-7280); Hee-won Park (https://orcid.org/0000-0002-7434-6675); Hyo-Rim Son (https://orcid.org/0000-0003-1704-0650); Mi-Suk Jin (https://orcid.org/0000-0001-9497-1809).

(c) This is an open-access article distributed under the terms of the Creative Commons Attribution Non-Commercial License (http://creativecommons.org/ licenses/by-nc/4.0) which permits unrestricted noncommercial use, distribution, and reproduction in any medium, provided the original work is properly cited. Copyright $\odot 2020$ by Korean Academy of Rehabilitation Medicine 


\section{INTRODUCTION}

The cardiac rehabilitation program is recommended for the primary and secondary prevention of cardiovascular diseases [1] and is a comprehensive rehabilitation service focusing on exercise therapy, including lifestyle changes, correction of risk factors, and psychological intervention [2]. Cardiovascular mortality has been shown to be significantly reduced in patients who underwent cardiac rehabilitation than in no-exercise controls [3]. In South Korea, the clinical guidelines for cardiac rehabilitation have recently been published to promote cardiac rehabilitation [4]. Nevertheless, the participation rate in cardiac rehabilitation programs is generally low despite the proven effectiveness of cardiac rehabilitation. The low participation rate in cardiac rehabilitation does not only concern a particular hospital, area, or country; a previous study reported that only $15 \%-30 \%$ of subjects participate in cardiac rehabilitation worldwide [5].

In cardiac rehabilitation, the barrier factor is an indicator that elucidates why patients with cardiovascular diseases cannot participate in cardiac rehabilitation programs. Various factors such as the lack of motivation or means of transportation, problems with distance or cost, physical problems, and workplace factors exist as barriers to cardiac rehabilitation worldwide [5]. Among these various barriers, several individuals cannot participate in cardiac rehabilitation because of distance. A previous study showed that distance and transportation problems were significant barriers to cardiac rehabilitation among attendees in South Korea [6]. In particular, the distance factor poses as a major barrier in rural areas [7].

Community-based cardiac rehabilitation (CBCR) can be regarded as one of the approaches to overcome the distance factor and sustain cardiac rehabilitation. The CBCR has not been implemented in South Korea; nonetheless, it is being conducted in numerous countries where cardiac rehabilitation is being performed. According to a survey of countries where cardiac rehabilitation was performed, $22.5 \%$ of countries offered the CBCR program [8]. In the CBCR program, the median number of exercise sessions was 20 (25th-75th percentile, 9.6-36), the frequency of the exercise program was 8 times per month, and the duration of the program was 2.5 months. Spatially, the community-based program was provided in public centers, which accounted for the highest percent- age at $56.9 \%$. In most cases, the providers or supervisors of the exercise program were exercise physiologists and physiotherapists. Exercise intensity was mostly assessed through the heart rate or subjective indicators such as Borg perceived exertion, with the use of telemetry for exercise monitoring being infrequent [8].

To introduce the CBCR, the program needs to be integrated into existing facilities and human resources in the community. Cardiac rehabilitation sites should be accessible to residents in each community in order for them to be able to regularly visit these sites 2-3 times per week for 2-3 months. Furthermore, equipment for exercise and the necessary workforce, including physical therapists and nurses, are required. In rural areas with low population density and several mountainous areas in Gangwon Province, public health institutions are worthy candidates. In South Korea, public health institutions, including 254 public health centers and 1,332 sub-health centers according to the 2018 Health and Welfare Statistical Yearbook, are installed nationwide [9].

Our hospital's cardiac rehabilitation team investigated the areas with the greatest number of individuals who refuse to participate in cardiac rehabilitation, excluding the city where our hospital is located. Majority of these individuals resided in Hongcheon-gun (Gangwon Province), which has the largest area among the guns in South Korea and is mostly rural. We developed a cardiac rehabilitation program for implementation in the community and conducted a provisional CBCR program at a public health center in Hongcheon-gun. In this study, we aimed to present the effects of CBCR as a health center model in South Korea.

\section{MATERIALS AND METHODS}

\section{Subjects}

Individuals aged $>40$ years with cardiovascular disease or its risk factors who were residing in Hongcheon-gun, Gangwon Province, were recruited as study subjects. This study was conducted from April to September 2018. The inclusion criteria for this study were as follows: individuals who had relevant diseases or at least two cardiovascular risk factors and could initiate moderate-intensity exercise without preparticipation medical clearance according to the recommendations of the American College of Sports Medicine (ACSM). (1) Subjects with known car- 
diovascular (cardiac, peripheral vascular, or cerebrovascular), renal, or metabolic (type 1 or 2 diabetes mellitus) disease who already performed regular exercises [10] or (2) those with no known cardiovascular, renal, or metabolic disease but with two or more risk factors [11] could continue with moderate-intensity exercise without medical clearance according the ACSM's guidelines. Current exercisers should have a history of performing planned, structured physical activity of at least moderate intensity for at least 30 minutes for 3 or more days per week during the past 3 months. Risk factors included age ( $\geq 45$ years for men, $\geq 55$ years for women), family history (myocardial infarction, coronary revascularization, or sudden death before 55 years of age in the father or other male firstdegree relative or before 65 years of age in the mother or other female first-degree relative), cigarette smoking (current cigarette smoker, those who quit within the previous 6 months, or those exposed to environmental tobacco smoke), sedentary lifestyle (non-participation in at least 30 minutes of moderate-intensity physical activity [ $40 \%$ to $<60 \% \mathrm{VO}_{2}$ reserve] for at least 3 days per week for at least 3 months), obesity (body mass index [BMI] $\geq 25$ $\mathrm{kg} / \mathrm{m}^{2}$ or waist circumference $>90 \mathrm{~cm}$ for men and $>85$ $\mathrm{cm}$ for women), hypertension, dyslipidemia (total cho- lesterol $\geq 200 \mathrm{mg} / \mathrm{dL}$, low-density lipoprotein cholesterol $[\mathrm{LDL}-\mathrm{C}] \geq 130 \mathrm{mg} / \mathrm{dL}$, high-density lipoprotein cholesterol [HDL-C] $<40 \mathrm{mg} / \mathrm{dL}$, or use of lipid-lowering medications), and prediabetes (hemoglobin Alc [HbAlc] of 5.7-6.4\%). HDL-C $\geq 60 \mathrm{mg} / \mathrm{dL}$ was considered a negative risk factor, and one positive risk factor was subtracted from the sum of positive risk factors [11]

The following were the exclusion criteria for this study: pain or discomfort in the chest, neck, jaw, arms, or other areas that might have resulted from ischemia; shortness of breath at rest or with mild exertion; dizziness or syncope; orthopnea or paroxysmal nocturnal dyspnea; ankle edema; palpitations or tachycardia; intermittent claudication; known heart murmur; or unusual fatigue or shortness of breath with usual activities [10]. Subjects with scores $<20$ on the Korean version of the Mini-Mental State Examination were also excluded.

We assumed that the change in maximal oxygen uptake as a result of the cardiac rehabilitation program would be $2.5 \pm 4.2 \mathrm{~mL} / \mathrm{kg} / \mathrm{min}$. Sample size was estimated as 25 with an alpha level of 0.05 and a beta level of 0.20 . We expected the drop-out rate to be $20 \%$, and the final sample size was calculated as 31 .

This study was conducted in accordance with the prin-

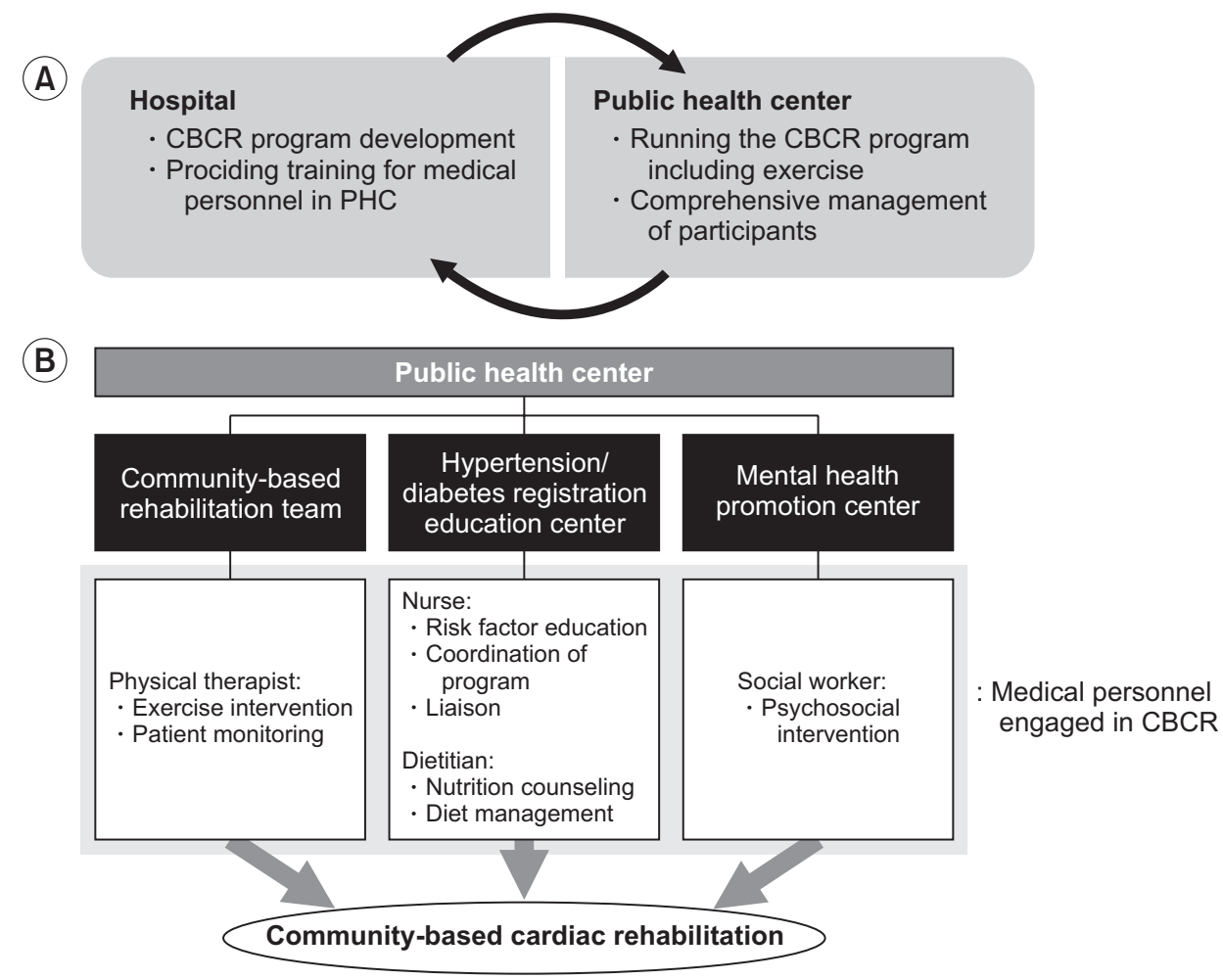

Fig. 1. (A) Relationship between the hospital and public health center as well as their roles in community-based cardiac rehabilitation (CBCR). (B) Medical personnel of the public health center (PHC) in Hongcheon-gun. 

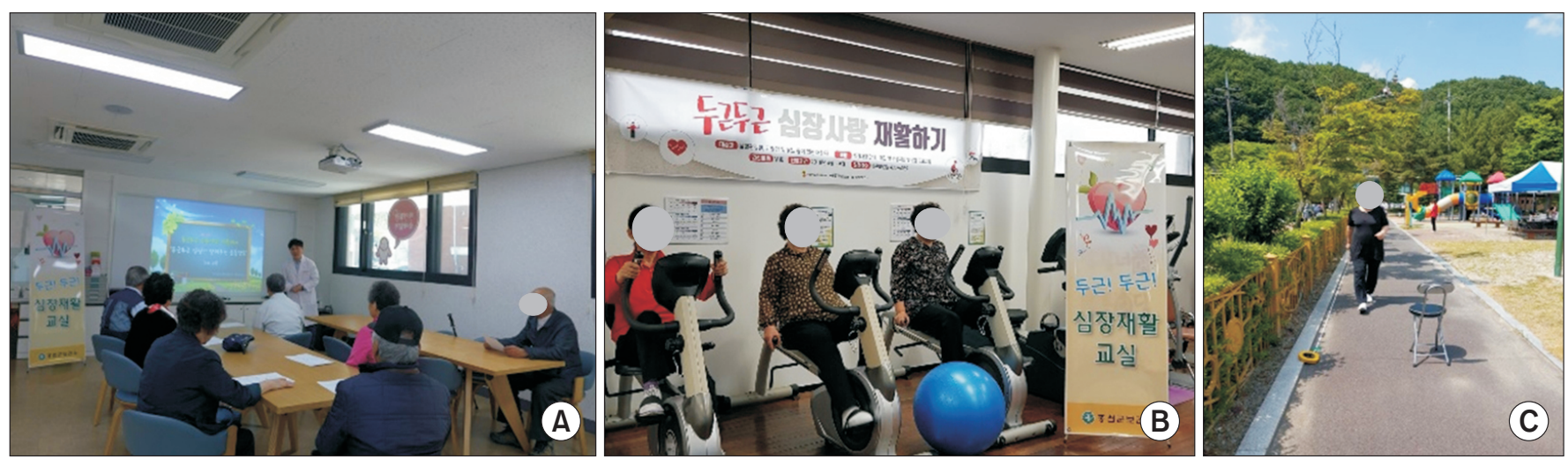

Fig. 2. The public health center in Hongcheon-gun. (A) Meeting room for education program. (B) Exercise room (area, approximately $50 \mathrm{~m}^{2}$ ) and equipment (4 stationary bikes, 10 gym balls, and 20 elastic bands) for the exercise program. (C) Adjacent park where the 6-minute walk distance test was conducted.

Table 1. Education and exercise program

\begin{tabular}{|c|c|c|c|}
\hline & & Education program & Exercise program \\
\hline \multicolumn{4}{|c|}{ Pre-assessment } \\
\hline \multirow[t]{10}{*}{ First half (10 wk) } & Week 1 & $\begin{array}{l}\text { Understanding heart diseases and } \\
\text { controlling risk factors }\end{array}$ & \multirow{8}{*}{$\begin{array}{l}\text { Frequency: twice a week } \\
\text { Exercise composition: } 30 \text {-minute aerobic } \\
\text { exercise/30-minute strengthening } \\
\text { exercise }\end{array}$} \\
\hline & Week 2 & $\begin{array}{l}\text { Exercises for heart disease prevention and } \\
\text { treatment }\end{array}$ & \\
\hline & Week 3 & Effects of cardiac rehabilitation & \\
\hline & Week 4 & - & \\
\hline & Week 5 & $\begin{array}{l}\text { Dietary education and counseling for } \\
\text { cardiovascular disease prevention I }\end{array}$ & \\
\hline & Week 6 & - & \\
\hline & Week 7 & Low-salt cooking practice & \\
\hline & Week 8 & - & \\
\hline & Week 9 & $\begin{array}{l}\text { Dietary education and counseling for } \\
\text { cardiovascular disease prevention II }\end{array}$ & \multirow{3}{*}{$\begin{array}{l}\text { Aerobic exercise } \\
\text { - Intensity: RPE 11-14 (moderate inten- } \\
\text { sity) } \\
\text { - Type: stationary bicycle, aero step }\end{array}$} \\
\hline & Week 10 & - & \\
\hline \multirow[t]{11}{*}{ Second half ( $10 \mathrm{wk})$} & Week 11 & Interim assessment & \\
\hline & Week 12 & - & \multirow{10}{*}{$\begin{array}{l}\text { Strengthening exercise } \\
\text { - Intensity: RPE 11-14 (moderate inten- } \\
\text { sity) } \\
\text { - Time: } 30 \text { minutes (upper extremity, } 15 \\
\text { minutes; lower extremity, } 15 \text { minutes) } \\
\text { - Type: elastic band/gym ball/dumbbell }\end{array}$} \\
\hline & Week 13 & $\begin{array}{l}\text { Psychosocial education: screening for } \\
\text { depression/anxiety }\end{array}$ & \\
\hline & Week 14 & - & \\
\hline & Week 15 & $\begin{array}{l}\text { Psychosocial education: high depression/ } \\
\text { anxiety risk group counseling }\end{array}$ & \\
\hline & Week 16 & - & \\
\hline & Week 17 & $\begin{array}{l}\text { Cardiovascular symptoms and coping } \\
\text { methods }\end{array}$ & \\
\hline & Week 18 & - & \\
\hline & Week 19 & Emergency management & \\
\hline & Week 20 & - & \\
\hline & & Post-assessment & \\
\hline
\end{tabular}

RPE, rating of perceived exertion. 
ciples embodied in the Declaration of Helsinki. In particular, the study protocol was approved by the Institutional Review Board of Kangwon National University Hospital (No. 2018-02-009), and written informed consent was obtained from all study subjects.

\section{CBCR program}

CBCR was carried out at the public health center in Hongcheon-gun, Gangwon Province. A cardiac rehabilitation program was constructed using human resources and equipment available at the health center in order to conduct it on a community basis. The medical staff who participated in this program and the exercise equipment are listed in Figs. 1 and 2, respectively. The program consisted of 10 education sessions and 20 weeks of customized exercises and was run for a total of 22 weeks ( 5 months), with 1 week for pre-assessment, 20 weeks for education and exercise, and 1 week for postassessment. Interim assessment was conducted during the 11th week of the program. The exercise program was regularly supervised by physical therapists, and exercises were performed twice a week at moderate intensity, with each exercise session lasting for 1 hour and comprising 30-minute aerobic exercise and 30-minute strengthening training (Table 1). The recommended rating for the perceived exertion score was no more than 11-14.

Blood pressure, chest pain, and respiratory difficulty were evaluated before and during each exercise and assessment session. Chest pain and respiratory difficulty were assessed using the angina scale ( $0=$ none, $1=$ little, $2=$ medium, $3=$ very, $4=$ extreme) and dyspnea scale ( 0 =none, 1 =little, $2=$ =medium, 3 =very, $4=$ =xtreme), respectively. To ensure the safety of the community-based exercise program, we set the criteria for not-participating/stopping exercise or assessment sessions by adapting the blood pressure and chest pain criteria of ACSM's indications for terminating exercise testing and indications and contraindications for inpatient and outpatient cardiac rehabilitation $[10,11]$. Subjects with blood pressure of at least $160 / 100 \mathrm{mmHg}$, score of $\geq 1$ on the angina scale, and score of $\geq 1$ on the dyspnea scale were not allowed to participate in exercise or assessment sessions. Exercise or assessment was stopped when the blood pressure was $\geq 250 / 115 \mathrm{mmHg}$, the angina scale score was $\geq 2$, and the dyspnea scale score was $\geq 3$, or if the subject wanted the exercise to be terminated. If there were a drop in systolic blood pressure (SBP) of $\geq 10 \mathrm{mmHg}$ with an increase in exercise intensity, the exercise or assessment session was discontinued.

\section{Outcome measurements}

Three evaluations were conducted prior to the program (pre-assessment, T0), at the 11th week of the program (interim assessment, T1), and after completion (post-assessment, T2) (Table 1). Waist circumference (cm), height $(\mathrm{cm})$, body mass $(\mathrm{kg})$, resting blood pressure $(\mathrm{mmHg})$, and resting heart rate (bpm) were measured. BMI was calculated as weight $(\mathrm{kg})$ divided by height squared $\left(\mathrm{m}^{2}\right)$. Fasting blood sugar (FBS; mg/dL), HbAlc (\%), LDL-C $(\mathrm{mg} / \mathrm{dL}), \mathrm{HDL}-\mathrm{C}(\mathrm{mg} / \mathrm{dL})$, total cholesterol $(\mathrm{mg} / \mathrm{dL})$, and triglyceride $(\mathrm{mg} / \mathrm{dL})$ were measured from blood samples.

The Korean Activity Scale/Index (KASI), which consists of 15 items, was used to estimate functional status [12]. For the KASI, the weight is used to calculate the score (range from 0 to 79 , with high scores indicating good functional status). Physical activity for 7 days was assessed using the Korean version of the International Physical Activity Questionnaire (IPAQ) short form [13]. We calculated MET-minute per week scores. The European Quality of Life-5 Dimension-3-Level version (EQ-5D$3 \mathrm{~L})$, which assesses mobility, self-care, usual activities, pain/discomfort, and anxiety/depression at three levels of functioning, was used to measure health-related quality of life [14]. The EQ-5D-3L index (range from - 0.171 to 1 , with higher values indicating better health status) was calculated using the valuation set by a previous report [15].

Exercise capacity was evaluated using the 6-minute walk distance (6MWD) test following the recommended guidelines [16]. The 6MWD test was performed by physiotherapists in accordance with the protocol outlined by the American Thoracic Society. The guideline recommends testing in a long corridor; however, owing to the absence of a long corridor at the public health center, we decided to conduct the 6MWD test on a track in a small park adjacent to the health center (Fig. 2C). Recently, a previous study has shown that 6MWD accurately estimates maximal oxygen uptake [17]. Peak $\mathrm{VO}_{2}(\mathrm{~mL} / \mathrm{kg} /$ $\mathrm{min}$ ) was estimated as $4.948+0.023 \times 6 \mathrm{MWD}(\mathrm{m})$.

\section{Statistical analysis}

The Mann-Whitney U test was used to compare young- 
old (65-74 years) and old-old ( $\geq 75$ years) women with respect to baseline characteristics, including height, body mass, BMI, waist circumference, resting SBP/DBP, resting HR, and number of risk factors. The Fisher exact test and chi-square test were employed for the comparison of the history of myocardial infarction and presence of diabetes mellitus, respectively, between young-old and old-old women. The results of evaluation at 3 points were analyzed using repeated-measures analysis of variance (ANOVA). For the post-hoc test, the Tukey method was employed. Comparison between young-old and oldold women was conducted on variables with significant

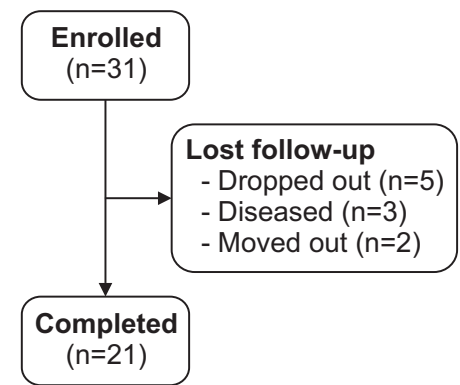

Fig. 3. Flow chart of inclusion.

Table 2. Baseline characteristics

\begin{tabular}{|c|c|c|c|c|}
\hline & \multirow{2}{*}{ All $(n=21)$} & \multicolumn{3}{|c|}{ Old female adult groups $(n=17)$} \\
\hline & & Young-old, 65-74 yr $(n=8)$ & Old-old, $\geq 75$ yr $(n=9)$ & p-value \\
\hline Age (yr) & $75.0 \pm 7.8(52-88)$ & $70.8 \pm 2.4(66-74)$ & $79.6 \pm 3.1(75-86)$ & - \\
\hline Sex, female & $18(85.7)$ & - & - & - \\
\hline Height (cm) & $154.26 \pm 6.04(141.6-166.9)$ & $154.73 \pm 5.02(146.4-160.6)$ & $151.13 \pm 5.43(141.6-157.8)$ & $0.236^{\mathrm{f})}$ \\
\hline Body mass (kg) & $59.55 \pm 11.29(37.5-80.1)$ & $66.51 \pm 11.00(45.5-80.1)$ & $52.16 \pm 9.41(37.5-64.6)$ & $0.006^{\mathrm{f})}$ \\
\hline $\operatorname{BMI}\left(\mathrm{kg} / \mathrm{m}^{2}\right)$ & $24.88 \pm 3.74(18.7-31.1)$ & $27.69 \pm 3.64(19.3-31.1)$ & $22.69 \pm 3.07(18.7-27.3)$ & $0.006^{\mathrm{f})}$ \\
\hline Waist circumference $(\mathrm{cm})$ & $86.7 \pm 11.0(68-109)$ & $92.88 \pm 11.09(70-109)$ & $80.44 \pm 9.18(68-94)$ & $0.018^{\mathrm{f})}$ \\
\hline Resting SBP (mmHg) & $130.5 \pm 12.6(105-150)$ & $129.3 \pm 9.0(117-140)$ & $126.0 \pm 14.3(105-145)$ & $0.773^{\mathrm{f})}$ \\
\hline Resting DBP (mmHg) & $73.2 \pm 11.2(49-92)$ & $78.8 \pm 6.9(70-89)$ & $68.1 \pm 12.9(49-92)$ & $0.038^{\mathrm{f})}$ \\
\hline Resting HR (bpm) & $75.0 \pm 6.8(67-90)$ & $74.8 \pm 6.8(67-85)$ & $77.1 \pm 7.9(68-90)$ & $0.630^{\mathrm{f})}$ \\
\hline Myocardial infarction & $1(6.3)$ & $1(12.5)$ & $0(0)$ & $0.274^{\mathrm{g})}$ \\
\hline Diabetes mellitus & $10(47.6)$ & $3(37.5)$ & $5(55.6)$ & $0.457^{\mathrm{h})}$ \\
\hline \multicolumn{5}{|l|}{ Risk factors } \\
\hline Age $^{\text {a) }}$ & $20(95.2)$ & $8(100)$ & $9(100)$ & \\
\hline Obesity ${ }^{\mathrm{b}}$ & $12(57.1)$ & $7(87.5)$ & $4(44.4)$ & \\
\hline Hypertension & $16(76.2)$ & $5(62.5)$ & $7(77.8)$ & \\
\hline Dyslipidemia $^{c}$ & $11(52.4)$ & $3(37.5)$ & $6(66.7)$ & \\
\hline Prediabetes ${ }^{\mathrm{d})}$ & $4(19)$ & $2(25)$ & $1(11.1)$ & \\
\hline High HDL-C ${ }^{\mathrm{e})}$ & $4(19)$ & $1(12.5)$ & $3(33.3)$ & \\
\hline Number of risk factors & $2.81 \pm 0.93(1-5)$ & $3.00 \pm 0.93(2-5)$ & $2.69 \pm 1.00(1-4)$ & $0.606^{\mathrm{f})}$ \\
\hline
\end{tabular}

Values are presented as mean \pm standard deviation (range) or number (\%).

BMI, body mass index; SBP, systolic blood pressure; DBP, diastolic blood pressure; HR, heart rate; HDL-C, high-density lipoprotein cholesterol.

${ }^{\text {a) }}$ Men $\geq 45$ years or women $\geq 55$ years.

${ }^{\text {b) }} \mathrm{BMI} \geq 25 \mathrm{~kg} / \mathrm{m}^{2}$ or waist girth $>90 \mathrm{~cm}$ for men and $>85 \mathrm{~cm}$ for women.

${ }^{\text {c) }}$ Total cholesterol $\geq 200 \mathrm{mg} / \mathrm{dL}$, low-density lipoprotein cholesterol $\geq 130 \mathrm{mg} / \mathrm{dL}, \mathrm{HDL}-\mathrm{C}<40 \mathrm{mg} / \mathrm{dL}$, or use of lipidlowering medications.

${ }^{\mathrm{d})}$ Hemoglobin Alc of 5.7\%-6.4\%.

${ }^{\text {e) }} \mathrm{HDL}-\mathrm{C} \geq 60 \mathrm{mg} / \mathrm{dL}$.

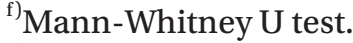

${ }^{g)}$ Fisher exact test.

${ }^{\text {h) }}$ Chi-square test. 
change between $\mathrm{T} 0$ and $\mathrm{T} 2$ in the post-hoc Tukey test. For these variables, the paired values measured at T0 and T2 were compared using the Wilcoxon rank test. The difference between $\mathrm{T} 0$ and $\mathrm{T} 2$ values was calculated and compared between young-old and old-old women using the Mann-Whitney U test. Statistical analysis was performed using jamovi version 1.1.9 (https://www.jamovi.org/), a free open-source graphical user interface for the R software, and $\mathrm{p}<0.05$ was considered statistically significant.

\section{RESULTS}

\section{Characteristics of subjects}

Out of 31 subjects, 21 completed the program (completion rate, $67.7 \%$ ). Altogether, 10 individuals (5 who dropped out, 3 who were admitted to the hospital, and 2 who moved out) were lost to follow-up (Fig. 3). None of the subjects, including the 10 individuals who were lost to follow-up, met the criteria for exclusion from or discontinuation of the exercise program due to an increase in blood pressure, angina scale score, and dyspnea scale score.
The baseline characteristics of subjects are summarized in Table 2. The average age of subjects was $75.0 \pm 7.8$ years; among the subjects, 1 was under 65 years of age (52 years old), 9 were $65-74$ years of age, and 11 were $\geq 75$ years of age. There were 18 female subjects $(85.7 \%)$. One patient had a history of myocardial infarction, and none had any cardiovascular disease (angina, arrhythmia, heart failure, cerebrovascular disease, or peripheral arteriosclerosis) or renal disease; 10 subjects had diabetes mellitus, and none had a family history of cardiac disorders. All subjects did not have a sedentary lifestyle and were performing moderate-intensity exercise more than 3 times per week. None of the subjects smoked.

Female subjects aged $\geq 65$ years $(n=17)$ were categorized into young-old (65-74 years; $n=8$ ) and old-old ( $\geq 75$ years; $\mathrm{n}=9$ ) women. Old-old women were lighter in weight and, thus, had a smaller BMI than young-old women $(\mathrm{p}<0.05)$. Furthermore, waist circumference and diastolic blood pressure were significantly smaller and lower, respectively, in old-old women (both $\mathrm{p}<0.05$ ). The old-old women were also shorter, albeit without statistically significant difference. No significant differences in the history of

Table 3. Outcomes including 6MWD, fasting blood sugar level, serum cholesterol level, and KASI in all subjects ( $\mathrm{n}=21$ )

\begin{tabular}{|c|c|c|c|c|c|c|c|c|}
\hline & TO & T & T? & $\mathbf{\Gamma}^{\mathbf{a})}$ & n & p-valu & ue of po & st hoc ${ }^{\text {b) }}$ \\
\hline & 10 & 11 & 12 & $F$ & e & T0-T1 & T0-T2 & T1-T2 \\
\hline $\mathrm{BMI}\left(\mathrm{kg} / \mathrm{m}^{2}\right)$ & $24.88 \pm 3.74$ & $24.58 \pm 3.72$ & $24.56 \pm 3.75$ & 7.800 & 0.001 & 0.006 & 0.003 & 0.974 \\
\hline SBP (mmHg) & $130.5 \pm 12.6$ & $128.9 \pm 10.3$ & $128.4 \pm 7.6$ & 0.271 & 0.764 & - & - & - \\
\hline Fasting blood sugar (mg/dL) & $127.7 \pm 26.7$ & $115 \pm 21.3$ & $106.8 \pm 13.0$ & 13.400 & $<0.001^{\text {c) }}$ & 0.009 & $<0.001$ & 0.120 \\
\hline $\operatorname{HbAlc}(\%)$ & $7.15 \pm 1.39$ & $7.00 \pm 1.04$ & $6.73 \pm 1.24$ & 2.150 & 0.130 & - & - & - \\
\hline Total cholesterol (mg/dL) & $161.8 \pm 41.5$ & $178.9 \pm 50.3$ & $168.0 \pm 53.3$ & 4.350 & 0.020 & 0.016 & 0.547 & 0.164 \\
\hline LDL-C (mg/dL) & $85.8 \pm 37.0$ & $88.7 \pm 41.5$ & $85.4 \pm 39.3$ & 0.173 & 0.842 & - & - & - \\
\hline HDL-C (mg/dL) & $51.7 \pm 17.4$ & $55.7 \pm 13.6$ & $53.1 \pm 15.0$ & 1.920 & 0.160 & - & - & - \\
\hline Triglyceride (mg/dL) & $119.4 \pm 83.1$ & $157.8 \pm 82.2$ & $125.1 \pm 59.0$ & 2.660 & 0.082 & - & - & - \\
\hline EQ-5D-3L index & $0.868 \pm 0.084$ & $0.862 \pm 0.074$ & $0.881 \pm 0.079$ & 0.930 & 0.403 & - & - & - \\
\hline IPAQ (MET-minute per week) & $1,596.8 \pm 1,044.5$ & $2,568.9 \pm 1,572.5$ & $2,366.1 \pm 1,489.5$ & 53.150 & 0.054 & - & - & - \\
\hline KASI score & $42.4 \pm 12.36$ & $48.23 \pm 11.98$ & $49.01 \pm 11.04$ & 3.120 & 0.055 & - & - & - \\
\hline 6MWD (m) & $461.25 \pm 39.43$ & $498.41 \pm 45.44$ & $520.44 \pm 53.34$ & 25.100 & $<0.001$ & $<0.001$ & $<0.001$ & 0.033 \\
\hline Estimated $\mathrm{VO}_{2 \max }(\mathrm{mL} / \mathrm{kg} / \mathrm{min})$ & $15.56 \pm 0.91$ & $16.41 \pm 1.05$ & $16.92 \pm 1.23$ & 25.100 & $<0.001$ & $<0.001$ & $<0.001$ & 0.033 \\
\hline
\end{tabular}

Values are presented as mean \pm standard deviation.

BMI, body mass index; SBP, systolic blood pressure; HbAlc, hemoglobin Alc; LDL-C, low-density lipoprotein cholesterol; HDL-C, high-density lipoprotein cholesterol; EQ-5D-3L, the European Quality of Life-5 Dimension-3-Level version; IPAQ, the International Physical Activity Questionnaire; KASI, the Korean Activity Scale/Index; 6MWD, 6-minute walk distance.

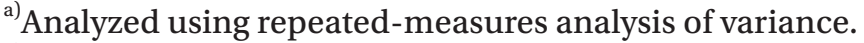

${ }^{\text {b) }}$ Post hoc analysis using the Tukey method.

${ }^{c)}$ Analyzed using Greenhouse-Geisser correction. 
myocardial infarction and presence of diabetes mellitus were noted between young-old and old-old women. Additionally, the number of risk factors did not differ between the two groups (Table 2).

\section{Outcomes of CBCR}

The outcomes of CBCR are summarized in Table 3. Resting SBP did not show a significant difference with time. The BMI and FBS significantly decreased according to $\mathrm{T} 0, \mathrm{~T} 1$, and $\mathrm{T} 2$. The $\mathrm{T} 0-\mathrm{T} 1$ and $\mathrm{T} 0-\mathrm{T} 2$ differences were significant; however, the T1-T2 difference was not. HbAlc tended to decrease, although this was not statistically significant. The total cholesterol level changed in a different pattern. The total cholesterol level increased during T0-T1 but decreased during T1-T2; these differences were significant, whereas the T0-T2 difference was not. Changes in LDL-C, HDL-C and triglyceride were not statistically significant.

The physical activity derived from the IPAQ showed an increasing trend, and the functional capacity assessed by the KASI gradually increased; nevertheless, these did not reach statistical significance. As for the EQ-5D-3L index results, no significant changes in the quality of life were observed.

The 6MWD was $461.25 \pm 39.43 \mathrm{~m}$ initially (estimated $\mathrm{VO}_{2}$, $15.56 \pm 0.91 \mathrm{~mL} / \mathrm{kg} / \mathrm{min}$ ) and increased to $520.44 \pm 53.34 \mathrm{~m}$ at post-assessment (estimated $\mathrm{VO}_{2}, 16.92 \pm 1.23 \mathrm{~mL} / \mathrm{kg} /$ min). This increase in 6MWD was statistically significant, and the changes in $\mathrm{T} 0-\mathrm{T} 1, \mathrm{~T} 0-\mathrm{T} 2$, and $\mathrm{T} 1-\mathrm{T} 2$ were significant as well.

\section{Young-old (65-74 years) versus old-old ( $\geq 75$ years)} women

As presented in Table 3, BMI, FBS, and 6MWD were
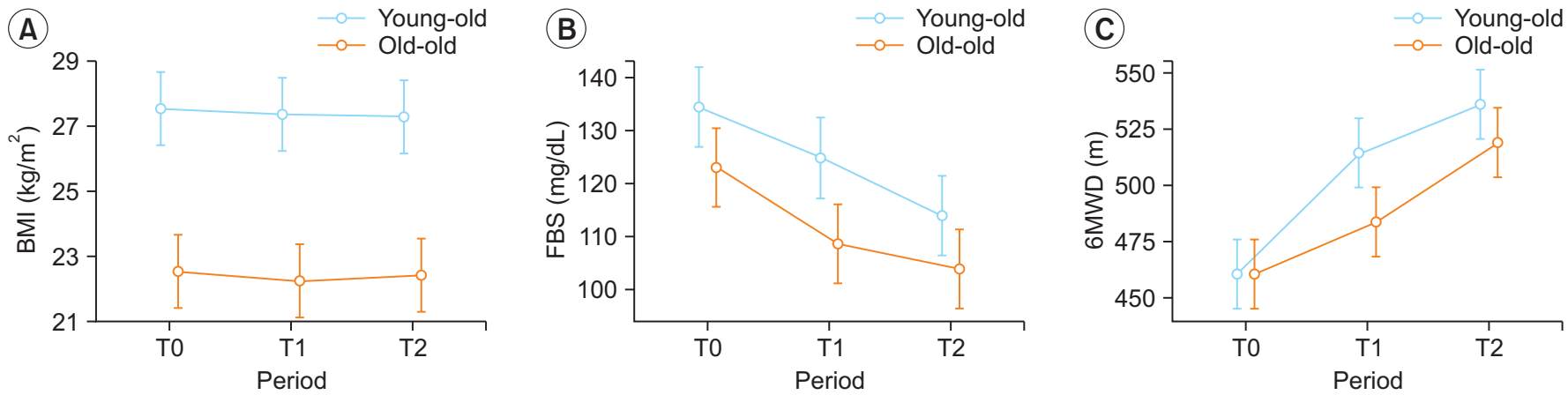

Fig. 4. Changes in (A) body mass index (BMI), (B) fasting blood sugar (FBS), and (C) 6-minute walk distance (6MWD) between young-old and old-old women.

Table 4. Young-old (65-74 years) versus old-old ( $\geq 75$ years) women

\begin{tabular}{|c|c|c|c|c|c|}
\hline & T0 & T2 & p-value ${ }^{\text {a) }}$ & $\Delta \mathrm{T} 2-\mathrm{T0}$ & p-value ${ }^{\text {b) }}$ \\
\hline $\operatorname{BMI}\left(\mathrm{kg} / \mathrm{m}^{2}\right)$ & & & & & 0.815 \\
\hline Young & $27.7 \pm 1.29$ & $27.5 \pm 1.31$ & 0.195 & $-0.24 \pm 0.14$ & \\
\hline Old & $22.7 \pm 1.02$ & $22.6 \pm 1.00$ & 0.369 & $-0.14 \pm 0.17$ & \\
\hline Fasting blood sugar (mg/dL) & & & & & 0.962 \\
\hline Young & $134.9 \pm 11.89$ & $114.4 \pm 6.05$ & 0.039 & $-20.50 \pm 9.22$ & \\
\hline Old & $123.4 \pm 6.87$ & $104.3 \pm 2.35$ & 0.015 & $-19.11 \pm 6.24$ & \\
\hline 6MWD (m) & & & & & 0.277 \\
\hline Young & $461.4 \pm 14.46$ & $536.4 \pm 19.01$ & 0.008 & $75.03 \pm 13.69$ & \\
\hline Old & $461.2 \pm 14.91$ & $519.9 \pm 16.48$ & 0.008 & $58.77 \pm 11.86$ & \\
\hline
\end{tabular}

Values are presented as mean \pm standard error.

BMI, body mass index; 6MWD, 6-minute walk distance.

${ }^{\text {a) }}$ Compared for paired values using the Wilcoxon rank test.

${ }^{\text {b) }}$ Compared between groups using the Mann-Whitney U test. 
the variables with significant changes between $\mathrm{T} 0$ and T2 in the post-hoc test. Fig. 4 shows the changes in BMI, FBS, and 6MWD at T0, T1, and T2 in young-old and oldold women. We compared the paired values measured at T0 and T2. The paired differences in FBS and 6MWD were significant in both young-old and old-old groups $(\mathrm{p}<0.05)$; however, the paired difference in BMI was not. For all variables, the changes between $\mathrm{T} 0$ and $\mathrm{T} 2$ were not significantly different between young-old and old-old women (Table 4).

\section{DISCUSSION}

In this study, we confirmed the effects of 20 -week CBCR-specifically the reduction in risk factors and the increase in exercise capacity. These results were significant not only in young-old women but also in old-old women. For safety reasons, we adopted the following pre-established criteria for exclusion from exercise: chest pain, dyspnea, and increased blood pressure. Although our subjects were old (average age, 75.0 years), none of the subjects were excluded from or discontinued the exercise program because of chest pain, dyspnea, and increased blood pressure.

The American Heart Association and the American Association of Cardiovascular and Pulmonary Rehabilitation recognize that all cardiac rehabilitation programs should contain the following core components: patient assessment, exercise training, dietary counseling, risk factor management (smoking, lipids, blood pressure, weight, and diabetes mellitus), and psychosocial intervention [2]. We included exercise training, risk factor management, dietary education, and psychosocial assessment as the core components in our program. Reducing risk factors is an important goal of cardiac rehabilitation. Age and family history are unmodifiable risk factors for cardiovascular diseases, whereas obesity, sedentary lifestyle, hypertension, dyslipidemia, and prediabetes can be changed through cardiac rehabilitation. In the present study, we had identified a reduction in body weight, BMI, and blood glucose level.

While conventional hospital-based cardiac rehabilitation is considered the standard approach, it is not the only option for cardiac rehabilitation. Community-based approaches also show similar effects to hospital-based cardiac rehabilitation and have been reported to be of relatively low cost and have high compliance [18-20]. For most potential candidates who do not participate in conventional hospital-based cardiac rehabilitation, the community is regarded as an alternative site for cardiac rehabilitation. Social conditions can influence appropriate forms of CBCR, and various venues for CBCR can be utilized, including community health centers [21], health clubs [22], sports centers [20], and YMCA [23].

This study was designed to evaluate the possibility of a public health center-based cardiac rehabilitation as a model of CBCR for either primary or secondary prevention. We defined the target population of CBCR as subjects who were allowed to perform moderate-intensity exercise that did not require a preparticipation medical screening test for the identification of underlying coronary artery disease. The study subjects were selected based on the criteria that include subjects suitable for either primary prevention [11] or secondary prevention [10]. Among study subjects, one with myocardial infarction was included, whereas others were eligible for primary cardiac rehabilitation. We expect that our CBCR program can be tried for both primary and secondary prevention. Further research is necessary to expand the target population of CBCR, if medical clearance by cardiac rehabilitation hospitals (or centers) prior to $\mathrm{CBCR}$ initiation could be received.

We confirmed the effectiveness of our program conducted in the public health center in Hongcheon-gun. We also found that this program was implemented without adverse events throughout the exercise and assessment sessions. Public health centers in South Korea have nurses and physical therapists, as well as their own exercise facilities [9]. Hence, we suggest the application of this public health center model in South Korea, considering that public health centers have the advantage of having both medical personnel and equipment, which need to be satisfied for the successful community-based operation of cardiac rehabilitation program.

Subjects can achieve further sustained effects through CBCR compared to traditional methods. Individuals can benefit from long-term attendance at CBCR programs [24], which can also be used as an avenue for continuing treatment after the completion of hospital-based phase 1 and 2 rehabilitation and CBCR. After cardiac rehabilitation at the hospital, if one continues to exercise without peer support, the amount of exercise will decrease; how- 
ever, if one has peer support, it will help maintain the exercise [25].

In community-based programs, the subject's age must be taken into consideration. As life expectancy increases and birth rate decreases, South Korea officially became an aged society in 2017 -that is, individuals aged $\geq 65$ years account for more than $14 \%$ of the total population. The pace of aging is expected to accelerate, and individuals aged 65 years or older may account for $46.5 \%$ of the country's population in 2067 [26]. Aging is further intensified in rural areas. In February 2020, the proportion of the aged population was $15.7 \%$ nationwide, whereas that in Gangwon Province was 19.9\%. The aging index of Hongcheon-gun was higher at 25.3\% [27].

Older adults constitute a large proportion of individuals with cardiovascular diseases. According to a retrospective cohort study of first-in-lifetime acute myocardial infarction patients with CR consultation at 11 tertiary hospitals in Korea, $34.1 \%(2,301$ out of 6,743$)$ of patients were over 70 years old [28]. Older adults have a lower participation rate in cardiac rehabilitation than younger adults. In a comparison of the results of 552 patients with acute coronary syndrome who received hospital-based cardiac rehabilitation in Korea, the mean ages of attendees and non-attendees were 58.9 and 63.9 years, respectively, with the age of non-attendees being significantly higher $(p<0.001)$ [6]. Older people perceived aging itself as a barrier to cardiac rehabilitation [6].

Nonetheless, the effect of cardiac rehabilitation is also significant in the older adult population. Cardiac rehabilitation was effective in both older adults over 65 years of age and those younger than 65 years [29] and showed improvements in exercise capacity, risk factors, and quality of life indicators in patients aged $\geq 65$ years [31]. However, studies on the effect of cardiac rehabilitation in older adults did not include a large number of subjects and were mainly small case series [30].

Few studies have investigated the effect of cardiac rehabilitation in very old adults aged $\geq 75$ years. In a recent meta-analysis that included 63 randomized controlled trials, the median age of 14,486 subjects was 56.0 years (range, 49.3-71.0 years) [3]. The proportion of older adults aged $\geq 75$ years in the community is expected to further increase in the near future. Therefore, it is meaningful to confirm the stability and effectiveness of community programs for older adults aged $\geq 75$ years. With respect to the effect of cardiac rehabilitation on exercise capacity, cardiac rehabilitation was not as effective in the old-old ( $\geq 75$ years) group as in the young-old (66-75 years) and middle-aged (45-65 years) groups [31]. Even with limited effect, very old adults aged $\geq 75$ years also benefited from cardiac rehabilitation. In an observational study of hospital-based cardiac rehabilitation performed for subjects aged $\geq 75$ years, peak $\mathrm{VO}_{2}$ and $6 \mathrm{MWD}$ were improved from baseline [32]. Similarly, our program resulted in a reduction in risk factors for cardiovascular diseases and led to an improvement in exercise capacity compared to baseline in both young-old women aged 64-74 years and old-old women aged $\geq 75$ years.

However, the CBCR program in public health centers may not be a sufficient solution for all patients due to the limited availability of such programs and participation barriers, including transportation issues. In our study, the final completion rate was $67.7 \%$, which was lower than expected, despite being conducted in Hongcheongun (dropout rate of $20 \%$, completion rate of $80 \%$ ). Public health centers are distributed throughout the nation; however, only one center is located in each city, gun, or gu. Taking Hongcheon-gun as an example, Hongcheongun is the largest gun in Korea, and most of its residents are very uncomfortable with transporting to farmlands and mountains. When planning for CBCR, distance should be considered first. If the driving distance is more than 30 minutes, participation in cardiac rehabilitation decreases [33]. Furthermore, expansion of the CBCR program to other community resources such as sub-health centers should be considered.

The present study has some limitations that should be addressed. Patients' referral system should be considered when implementing CBCR; however, we did not include this in our study. To evaluate the initial application and effectiveness of cardiac rehabilitation program in the community, we recruited volunteers from the public health center in Hongcheon-gun but did not include those from the hospital because of their refusal. Hence, we did not investigate the referral between the hospital and the community health center. In order to successfully implement CBCR, a linkage system should be established between hospitals providing acute care and community organizations conducting cardiac rehabilitation. This study aimed to develop a CBCR program and confirm its effectiveness, and our subjects were primarily selected 
from the community, not referred from acute care hospitals. The referral system between the community and acute hospital should be investigated in the future.

In conclusion, we reported the first attempted CBCR in a health center in South Korea. Public health centers have their own medical personnel and exercise facilities. We propose target selection and exclusion criteria suitable for community management, as well as those who can safely participate in the program. Our program resulted in a reduction in risk factors for cardiovascular diseases and led to an improvement in exercise capacity, which were confirmed not only in young-old women aged 65-74 years but also in old-old women aged $\geq 75$ years.

\section{CONFLICT OF INTEREST}

No potential conflict of interest relevant to this article was reported.

\section{ACKNOWLEDGMENTS}

This work was supported by the National Research Foundation of Korea (NRF) grant funded by the Korean government (MSIT) (No. NRF-2017R1C1B5076976).

\section{AUTHOR CONTRIBUTION}

Conceptualization: Baek S, Park H. Methodology: Baek S, Ha Y, Mok J, Son HR, Jin MS. Funding acquisition: Baek S. Writing - original draft: Baek S, Ha Y. Writing - review and editing: Baek S. Approval of the final manuscript: all authors.

\section{REFERENCES}

1. Perk J, De Backer G, Gohlke H, Graham I, Reiner Z, Verschuren WM, et al. European guidelines on cardiovascular disease prevention in clinical practice (version 2012): the fifth joint task force of the European society of cardiology and other societies on cardiovascular disease prevention in clinical practice (constituted by representatives of nine societies and by invited experts). Int J Behav Med 2012;19:403-88.

2. Balady GJ, Williams MA, Ades PA, Bittner V, Comoss P, Foody JM, et al. Core components of cardiac rehabilitation/secondary prevention programs: 2007 update.
Circulation 2007;115:2675-82.

3. Anderson L, Oldridge N, Thompson DR, Zwisler AD, Rees K, Martin N, et al. Exercise-based cardiac rehabilitation for coronary heart disease: Cochrane systematic review and meta-analysis. J Am Coll Cardiol 2016;67:1-12.

4. Kim C, Sung J, Lee JH, Kim WS, Lee GJ, Jee S, et al. Clinical practice guideline for cardiac rehabilitation in Korea. Ann Rehabil Med 2019;43:355-443.

5. Neubeck L, Freedman SB, Clark AM, Briffa T, Bauman A, Redfern J. Participating in cardiac rehabilitation: a systematic review and meta-synthesis of qualitative data. Eur J Prev Cardiol 2012;19:494-503.

6. Im HW, Baek S, Jee S, Ahn JM, Park MW, Kim WS. Barriers to outpatient hospital-based cardiac rehabilitation in Korean patients with acute coronary syndrome. Ann Rehabil Med 2018;42:154-65.

7. Angelis CD, Bunker S, Schoo A. Exploring the barriers and enablers to attendance at rural cardiac rehabilitation programs. Aust J Rural Health 2008;16:137-42.

8. Ghisi GLM, Pesah E, Turk-Adawi K, Supervia M, Jimenez FL, Grace SL. Cardiac rehabilitation models around the globe. J Clin Med 2018;7:260.

9. Ministry of Health and Welfare. Health and welfare statistical yearbook 2018. Sejong, Korea: Ministry of Health and Welfare; 2018.

10. American College of Sports Medicine. ACSM's guideline for exercise testing and prescription. 10th ed. Philadelphia, PA: Wolters Kluwer; 2018.

11. American College of Sports Medicine. ACSM's guideline for exercise testing and prescription. 9th ed. Philadelphia, PA: Lippincott Williams \& Wilkins; 2013.

12. Sung J, On YK, Kim HS, Chae IH, Sohn DW, Oh BH, et al. Development of Korean Activity Scale/Index (KASI). Korean Circ J 2000;30:1004-9.

13. Oh JY, Yang YJ, Kim BS, Kang JH. Validity and reliability of Korean version of International Physical Activity Questionnaire (IPAQ) short form. J Korean Acad Fam Med 2007;28:532-41.

14. Kim MH, Cho YS, Uhm WS, Kim S, Bae SC. Crosscultural adaptation and validation of the Korean version of the EQ-5D in patients with rheumatic diseases. Qual Life Res 2005;14:1401-6.

15. Lee YK, Nam HS, Chuang LH, Kim KY, Yang HK, Kwon IS, et al. South Korean time trade-off values for EQ-5D health states: modeling with observed values for 101 
health states. Value Health 2009;12:1187-93.

16. ATS Committee on Proficiency Standards for Clinical Pulmonary Function Laboratories. ATS statement: guidelines for the six-minute walk test. Am J Respir Crit Care Med 2002;166:111-7.

17. Ross RM, Murthy JN, Wollak ID, Jackson AS. The six minute walk test accurately estimates mean peak oxygen uptake. BMC Pulm Med 2010;10:31.

18. Richardson G, van Woerden HC, Morgan L, Edwards R, Harries M, Hancock E, et al. Healthy hearts: a community-based primary prevention programme to reduce coronary heart disease. BMC Cardiovasc Disord 2008;8:18.

19. Kubilius R, Jasiukeviciene L, Grizas V, Kubilien $\nabla$ L, Jakubseviciene E, Vasiliauskas D. The impact of complex cardiac rehabilitation on manifestation of risk factors in patients with coronary heart disease. Medicina (Kaunas) 2012;48:166-73.

20. Mosleh SM, Bond CM, Lee AJ, Kiger A, Campbell NC. Effects of community based cardiac rehabilitation: comparison with a hospital-based programme. Eur J Cardiovasc Nurs 2015;14:108-16.

21. Zhang L, Zhang L, Wang J, Ding F, Zhang S. Community health service center-based cardiac rehabilitation in patients with coronary heart disease: a prospective study. BMC Health Serv Res 2017;17:128.

22. Mandic S, Body D, Barclay L, Walker R, Nye ER, Grace SL, et al. Community-based cardiac rehabilitation maintenance programs: use and effects. Heart Lung Circ 2015;24:710-8.

23. Hutchinson K. Community-based cardiac rehabilitation: a YMCA model. ACSMs Health Fit J 2006;10:21-7.

24. Mandic S, Hodge C, Stevens E, Walker R, Nye ER, Body D, et al. Effects of community-based cardiac rehabilitation on body composition and physical function in individuals with stable coronary artery disease: 1.6year followup. Biomed Res Int 2013;2013:903604.

25. Clark AM, Munday C, McLaughlin D, Catto S, McLaren A, Macintyre PD. Peer support to promote physical activity after completion of centre-based cardiac rehabilitation: evaluation of access and effects. Eur J
Cardiovasc Nurs 2012;11:388-95.

26. Korean Statistical Information Service. Estimated population by age group (production age population, elderly population) [Internet]. Daejeon, Korea: Korean Statistical Information Service; 2019 [cited 2020 Oct 30]. Available from: https://kosis.kr/statisticsList/ statisticsListIndex.do?menuId=M_01_01\&vwcd=MT_ ZTITLE\&parmTabId=M_01_01\#SelectStatsBoxDiv.

27. Korean Statistical Information Service. Ratio of the elderly population (metropolitan-city or province/ city/gun/gu). Daejeon, Korea: Korean Statistical Information Service; 2020 [cited 2020 Oct 30]. Available from: https://kosis.kr/statHtml/statHtml. do?orgId=101\&tblId=DT_1YL20631.

28. Kim C, Choi I, Cho S, Han JY, Kim AR, Kim WS, et al. Cardiac rehabilitation and 5-year mortality after acute myocardial infarction: report from 11 tertiary hospitals in Korea (ETHIK Study). Eur J Phys Rehabil Med 2020;56:489-95.

29. Kim KH, Jang YC, Song MK, Park HK, Choi IS, Han JY. Changes in aerobic capacity over time in elderly patients with acute myocardial infarction during cardiac rehabilitation. Ann Rehabil Med 2020;44:77-84.

30. Pasquali SK, Alexander KP, Peterson ED. Cardiac rehabilitation in the elderly. Am Heart J 2001;142:74855.

31. Marchionni N, Fattirolli F, Fumagalli S, Oldridge N, Lungo FD, Morosi L, et al. Improved exercise tolerance and quality of life with cardiac rehabilitation of older patients after myocardial infarction: results of a randomized, controlled trial. Circulation 2003;107:2201-6.

32. Baldasseroni S, Pratesi A, Francini S, Pallante R, Barucci $\mathrm{R}$, Orso $\mathrm{F}$, et al. Cardiac rehabilitation in very old adults: effect of baseline functional capacity on treatment effectiveness. J Am Geriatr Soc 2016;64:1640-5.

33. Bakhshayeh S, Sarbaz M, Kimiafar K, Vakilian F, Eslami S. Barriers to participation in center-based cardiac rehabilitation programs and patients' attitude toward home-based cardiac rehabilitation programs. Physiother Theory Pract 2019:1-11. 